\title{
Educational Supervisory System based on Intelligent Multi-Agents
}

\author{
A. F. El-Gamal \\ Dept. of Computer Teacher \\ Preparation \\ Faculty of Specific Education \\ Mansoura University
}

\author{
A. E. Amin \\ Dept. of Computer Teacher \\ Preparation \\ Faculty of Specific Education \\ Mansoura University
}

\author{
B. E. Mohamed \\ Dept. of Computer Teacher \\ Preparation \\ Faculty of Specific Education \\ Mansoura University
}

\begin{abstract}
This research has focused on studying The Educational Multiagent System extensively to solve the problems of following up the daily performance of the student in relation to school activities and evaluation. The proposed system consists of four agents: Interface Agent, Data Management Agent, Supervisory Agent and Communication Agent. They are connected with each other by Agent Communication Language (ACL) including Knowledge Query and Manipulation Language (KQML). This system has been applied to a primary school with respect to the students of first, second and third grades. The proposed system improves the communication process between the school staff and parents that occurs an improvement of the scores obtained by these students and in a way that raised the performance rate by teachers and students.
\end{abstract}

\section{Keywords}

Multi-Agen System (MAS), agents, supervision system, Agent Communication Language (ACL), Knowledgebase, Knowledge Query and Manipulation Language (KQML), intelligent agent.

\section{INTRODUCTION}

The evolution of multi-agent systems represents an extra ordinary opportunity for education, because they are capable of managing and organizing information, tasks and making important decisions on behalf of their users. Agent technology appears to be a promising approach to address the challenges of modern educational environments [1] such as the weak communication between the school staff and parents and the lack of follow up by parents.

Multi-Agent systems are composed of autonomous hardware/software agents that have to achieve required tasks [2]. Through the collaboration between different agents, my aim is to achieve a highly efficient, flexible, customizable system that provides better communication, interaction and management among all users engaged in the academic institutions [3].An agent is an autonomous entity that has behavior conducted by objectives. Each agent can perceive and act over an environment. Agents are built to solve problems in several application domains for example intelligent tutoring systems, E-learning and educational applications [4].

Intelligent agents or software agents are programmed software entities that carry out a series of operations on behalf of a user or another program with some degree of autonomy. A MultiIntelligent Agent (MIA) is a collection of autonomous agents which interact with each other or with their environments to achieve one or more objectives [5]. As for Multi-agent system, the agents communicate with each other in order to achieve their task and exchange messages with each other [3]

Agents in a multi-agent system (MAS) are capable of interacting and communicating with each other. This usually requires a common language; an Agent Communication Language (ACL) [6].A standard agent communication language (ACL) carefully defines the overall structure and standard Patterns of interaction between agents in an extensible way [7]

Agent technology introduced collaborative agents that comprise a network, communicating by means of a high level query language KQML (Knowledge Query and Manipulation Language) [8] and it is a language that is designed to support interactions among intelligent software agents [9]. In addition, it was developed by the Advanced Research Projects Agency (ARPA) supported Knowledge Sharing Effort and independently implemented by several research groups. It has been successfully used to implement a variety of information systems using different software architectures [10].

The goal of this study is to suggest intelligence Educational Supervision System (ESS) through multi agents to follow up student's daily performance and to strengthen the communication process between the school staff and parents. This runs through communication management and message processing mechanisms between school staff (admins, teachers) and parents. Each agent has the ability to communicate with other system agents to do the required task.

\section{MULTI-AGENT BASED SYSTEM}

Agents must be appropriate to the environment through which it works for meeting the design objectives [11]. Agents in dynamic environments cause change rapidly in relation to the task required to be able to communicate with each other for accomplishing the required task as shown in figure1

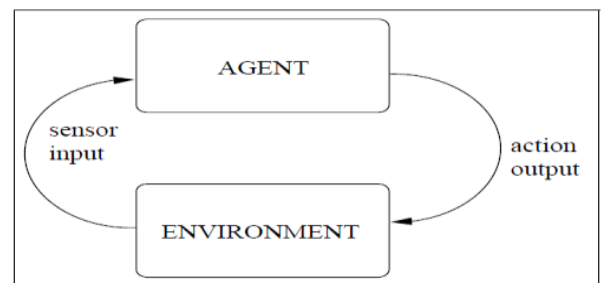

Fig 1: Interaction between agents and its environment

The agent takes the inputs from the surrounding environment then it carries out certain processes to get the outputs directed to this surrounding environment [12]. 


\section{Therefore, agents are characterized to be:-}

(1)Goal oriented that means that it is made for accomplishing its goal that is represented by the required task.

(2) Cooperative with other agents which means that it is able to communicate and integrate with other agents for sharing knowledge to negotiate a common strategy.

(s)Compatible with the changing dynamic environment [13] .

Nowadays, the importance of multi-agent systems is getting wider especially as far the educational fields that suffer from weak follow up and supervision as well as the lack of communication between the school staff and parents.

The structure of multi-agent systems authorize development of agent based technology for improving the methodologies of agents in relation to developing the educational systems such as E-Learning, follow up of students 'educational process by teachers and parents and the use of these methodologies in education is not an easy task. Furthermore, the methodologies of multi-agents can bring about several advantages to the application of educational systems where they can provide a good learning environment. Also, they improve the evaluation techniques used by schools in relation to follow up of the student's at school through the participation by parents in the follow up process [14].

\section{AGENT COMMUNICATION LANGUAGE (ACL)}

The communication processes between agents are represented by two kinds: agent/user communication and inter-agent communication. Agent communicates with the users to receive their requests and agent communicates with other agents to exchange message and information's [15]. Two agents can communicate through ACL; that is designed carefully to define the overall structure and standard patterns of interaction between agents and the main purpose of it is to facilitate communication between agents in a multi-agent system [7].

The ACL is thought as a communication protocol (or a collection of protocols) that supports many message types [9]. KQML one of the most widely used ACLs in multi-agent systems; this language has been very successful in facilitating the communication and coordination of software agents in a variety of domains [6] KQML Message can be identified into three layers: Content, Communication and Message [16] as shown in figure2.

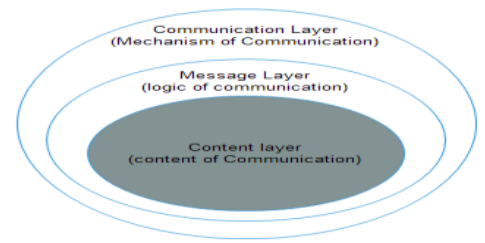

Fig 2: KQML Layers

KQML has a set of per-formatives that is commonly used in the communication process as shown in figure 3. Performatives define the syntax for a collection of messages that allow agents to send and receive messages [17].

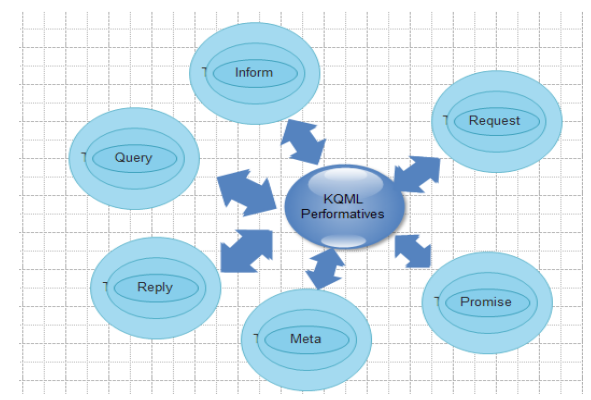

Fig 3: KQML per-formatives

\section{PROPOSED SYSTEM}

The Proposed Educational Supervisory System (ESS) is based on supervision model; the purpose of this model is a guidance to enhance quality of supervision elementary pupils. The system consists of four agents; Interface Agent (IA), Data Management Agent (DMA), Supervisory Agent (SA) and Communication Agent (CA). As shown in Figure 4.

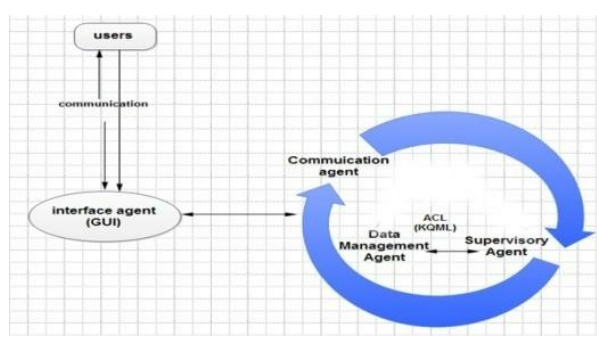

Fig 4: System Agents

Each agent has its own life cycle that starts with receiving the request. Then, it communicates with the other agents to achieve the required task. Therefore, there is an output in response to the above mentioned request.

Interface Agent is considered as the system kernel because it is characterized to be effective, collaborative and flexible for each user. It is used in the proposed system to make the best use of the system abilities as well as helping users to carry out tasks in an easy and comfortable way. Furthermore, IA is represented by Graphical User Interface (GUI) and facilitated the access by users to the system in an efficient way. Besides the permissions of users (Administrators, supervisors, Teachers and parents) are used for navigate into the system, inserting queries and obtaining results.

As for admin, he can access the management area to manage school grades (classes, schedules, subjects...... etc.), manage users accounts and students logs (add/edit student information, absence, exam marks) Admin activity diagram is shown in Appendix A.

Teachers can access to the system to know the available to the students in his classes. In additions, edit monthly evaluation of his students and recording the absent students as well as sending message to the parents on their mobile phones. Teacher activity diagram is shown in Appendix A.

As for parents, they can access the system to navigate between their children records (daily home works, exam marks, absence records, schedule ... etc.) as shown in figure 5 that is a use case diagram for parent. 


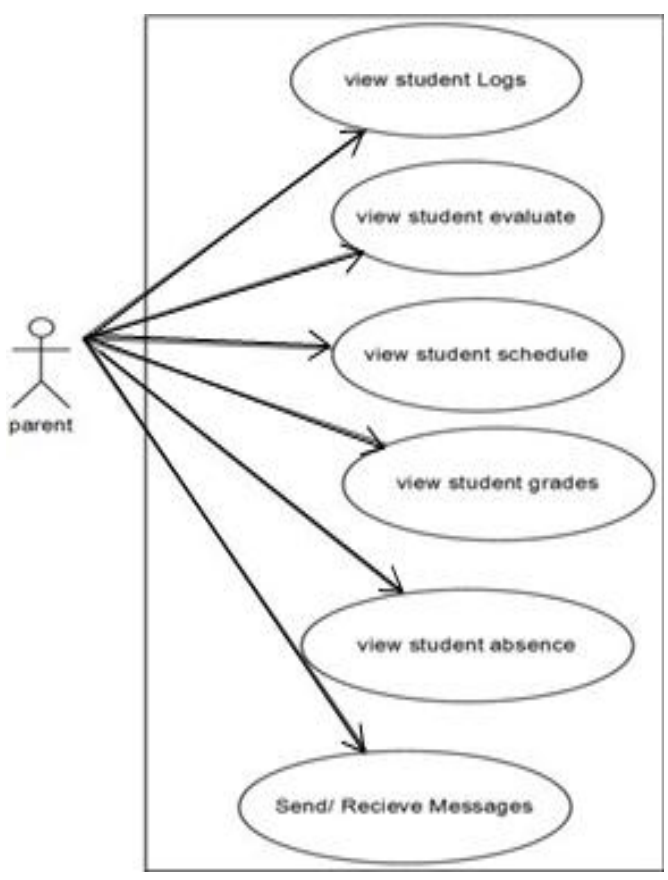

Fig 5: Parent use case diagram

Data Management Agent is the fundamental agent that manages the school database structure and supports other agents with suitable and appropriate data without errors with respect to queries of the database as shown in figure 6

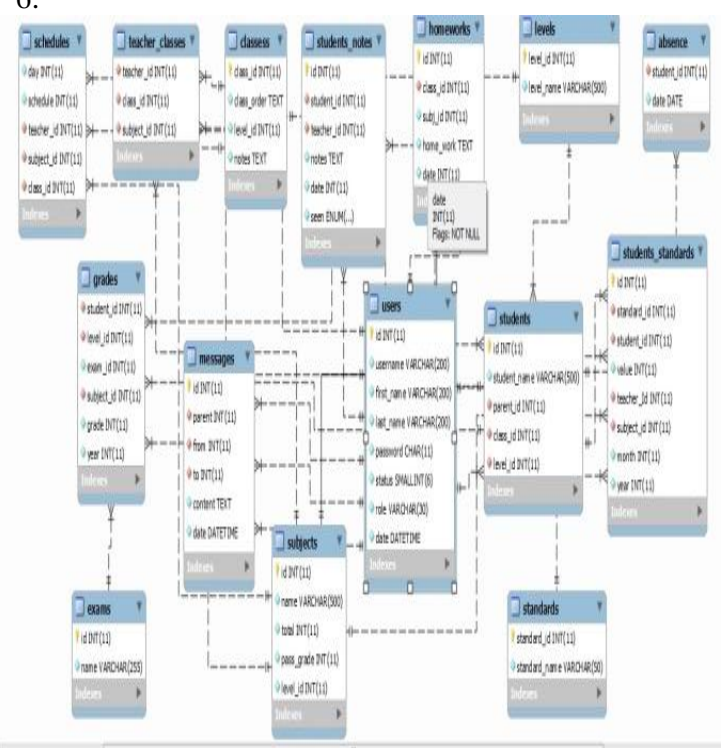

Fig 6: Database Structure

Operations performed by DMA are done by a standard method of running queries through implementing the basic operations of the database including (insert, update, delete).DMA saves time and effort when dealing with all data of the school and students. In addition, it provides smart solutions to the problems connected with the system database.

Supervisory Agent contains the knowledgebase of the system which includes facts and rules. Rules are the essential part inside $\mathbf{S A}$ that applies in the fact existing into the system to make suitable decision.

Furthermore, the teacher enters the values related to students' monthly evaluation includes (activities, oral, attending) which are executed by the rules to produce the suitable decision. Then SA sends messages to parents and saves them in database. The following part shows pseudo code for evalustion process.

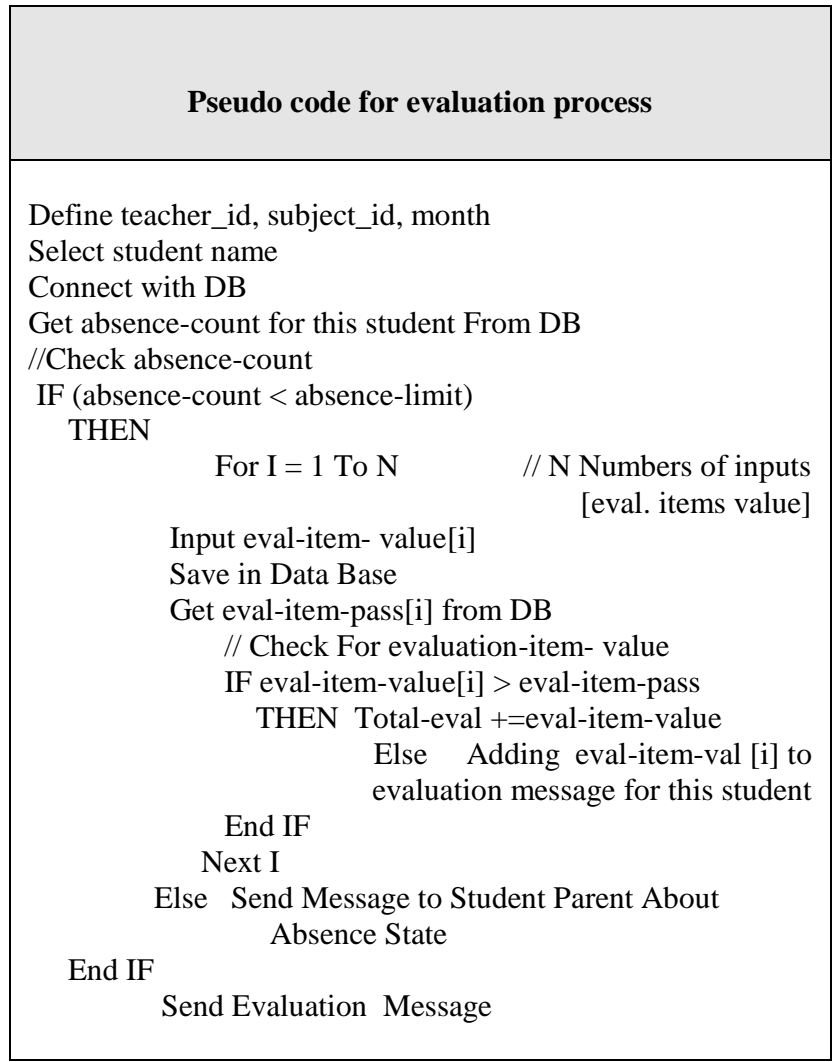

Communication Agent plays a very important role in the communication conducted among the other software agent. Each software agent is represented by one or more classes. Each class consists of attributes that include the arguments and functions which depend on the attributes to carry out the required task as shown in figure 7 which represents system class diagrams. 


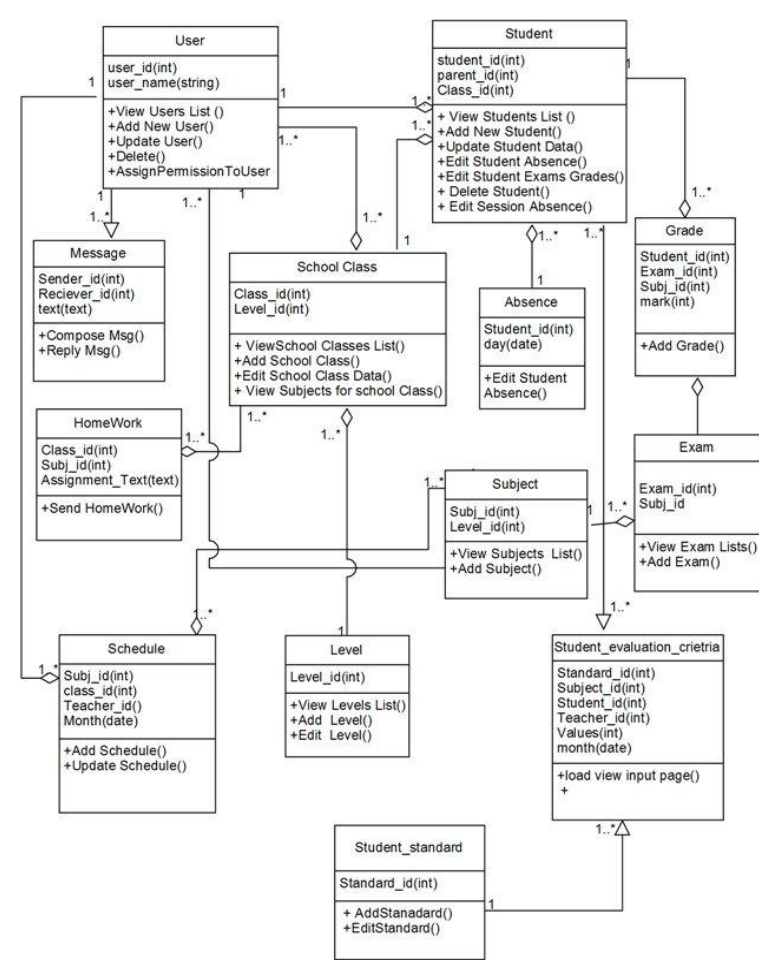

Fig 7: System Class Diagram

\section{EXPERIMENTAL WORK}

ESS is developed by assisting of PHP Storm Editor and embedded database using MYSQL. It is basically based on open source web application framework called "CodeIgniter", it is a Model View Controller (MVC) web framework based on Object Oriented Programming (OOP). Appendix B represent sample of the proposed software screen.

The proposed system has been applied on the first, two and three year students of the elementary school, "Elwady" Languages School for Girls, with a total of 150 students, divided by 20 students per each class (1/A, 2/A and 3/A).

- Users (Teachers, Parents, supervisors and Admins) can interact with the system GUI. User's privileges are checked to display the suitable interface and save information about user login.

- After the admin login, the main menu will appear containing all functions to manage users' data (APPENDIX B illustrates the users list screen).

- One of the teacher's privileges is that he can manage all students' (APPEDIX B illustrates students data management screen).

- Teacher can enter the values of evaluation as for his subject for available students by clicking the "Evaluate" button (APPENDIX B illustrates GUI for entering evaluation values).

- By clicking "Send" button, the evaluation items degrees in relation to this subject is saved in database then system checks these items. If they are less than specified value, the system will send a total message contains all failed evaluation item degrees to student's parent automatically. (APPENDIX B illustrates message for "Student Evaluation").

- When a parent has access the system with his privileges, the main screen appears to him as for incoming messages (APPENDIX B illustrates the inbox message for parent).

- $\quad$ By clicking one of these messages, he can see it and has the ability to reply. (APPENDIX B illustrates reply about "Student Absence").

\section{CONCLUSION}

Schools must improve their basic functions of teaching and learning process that aims at helping and empowering all students to raise their broad outcomes. This improvement through instructional enhancement supervision responsible for the highest performance of students in school. Educational supervision is the way to ensure the student performs good progress.

In this paper, an educational supervisory system is introduced. It is based on intelligent multi-agents that used communication between web and mobile application. It composed of four agents (interface, data management, supervisory and communication agent) that integrate with each other.

The proposed system based on the model of supervision that monitors the academic student performance through record student attendance, daily assignment, school schedules and exams marks. Also the system outputs contained daily reports about assignments, absence, and exam marks

There are significant effect for educational supervisory system in developing the communication methods between schools staff and parents that help on student evaluations to raise the academic students' performance.

\section{REFERENCES}

[1] Safiye TURGAY, "a multi-agent system approach for distance learning architecture ", The Turkish Online Journal of Educational Technology, TOJET ISSN: 13036521 vol 4 , October 2005

[2] Jean-Paul Jamont, Michel Occello "A selforganizationprocess for communication management in embedded multi-agent systems", IEEE/WIC/ACM International Conference on Intelligent Agent technology, IEEE Computer Society, pp.51-55, 2007.

[3] Dr. Prashant M. Dolia, "Integrating Ontologies into Multi-Agent Systems", JOURNAL OF EMERGING TECHNOLOGIES IN WEB INTELLIGENCE, VOL. 2, NO. 1, FEBRUARY 2010.

[4] Henri Avancini, Analía Amandi, "A Java Framework for Multiagent Systems", SADIO Electronic Journal of Informatics and Operations Research, vol. 3, no. 1, pp. 1-12,2000

[5] M. A. Kadhim,M. A.A. H. Kaur," A Multi-intelligent Agent Architecture for Knowledge Extraction: Novel Approaches for Automatic Production Rules Extraction". International Journal of Multimedia and Ubiquitous Engineering pp.95-114, Vol.9, No.2 2014

[6] MaryBerna-Koes,IllahNourbakhsh,KatiaSycara "Communication Efficiency in Multi-Agent Systems ".

[7] Martin L. Griss, "Software Agents as Next Generation Software Components", Software Agents as Next Generation Software Components,2001.

[8] Christopher G Marks, B. S, "Extensible Multi-Agent System forHeterogeneous Database Association Rule Mining and Unification." Master Thesis. Department of computer system.1999. 
[9] James Mayfield Yannis Labrou Tim Finin"Evaluation of KQML as an Agent Communication Language", Computer science and electrical engineering department, University of Maryland Baltimore County,1996.

[10] Finin, T., Y. Labrou, Agent Communication Languages, "AgentCommunication Languages Tutorial, University of Maryland Baltimore County, October,1999.

[11] michel wooldridg "agent based computing", Dept. of Electronic Engineering, Queen Mary \& Westfield College University of London, London, September 29, 1997.

[12] James Odell, James Odell Associates, Ann Arbor, H. Van Dyke Parunak, Mitchell Fleischer, "Modeling Agents and their Environment: The Communication Environment", JOURNAL OF OBJECT ECHNOLOGY, Vol. 2, No. 3, May-June 2003.

[13] G. B. Nunes, A. Cardoso1, A. Santos1,2, P. Gil1,3 "MULTIAGENT BASED ARCHITECTURE FOR ROBUST SUPERVISION OVER WIRELESS SENSOR NETWORKS"
[14] Vera Maria B. Werneck, Rosa Maria E. Moreira Costa1 and Luiz Marcio Cysneiros, "Modelling Multi-Agent System using Different Methodologies", 502 pages, April, 2011.

[15] Karim Bouzouba1, Bernard Moulin2, Adil Kabbaj3, "CG-KQML+: An Agent Communication Language and its use in a Multi-Agent System", Computer Science Department and Research Center on Geomatics, Laval University.

[16] Tim Finin ,Don McKay,Rich Fritzson, "An Overview of KQML:AKnowledge Query and Manipulation Language",March 2, 1992.

[17] Cyprian Foinjong Ngolah, "a tutorial on agent communication and knowledge sharing ",university of calgary. 


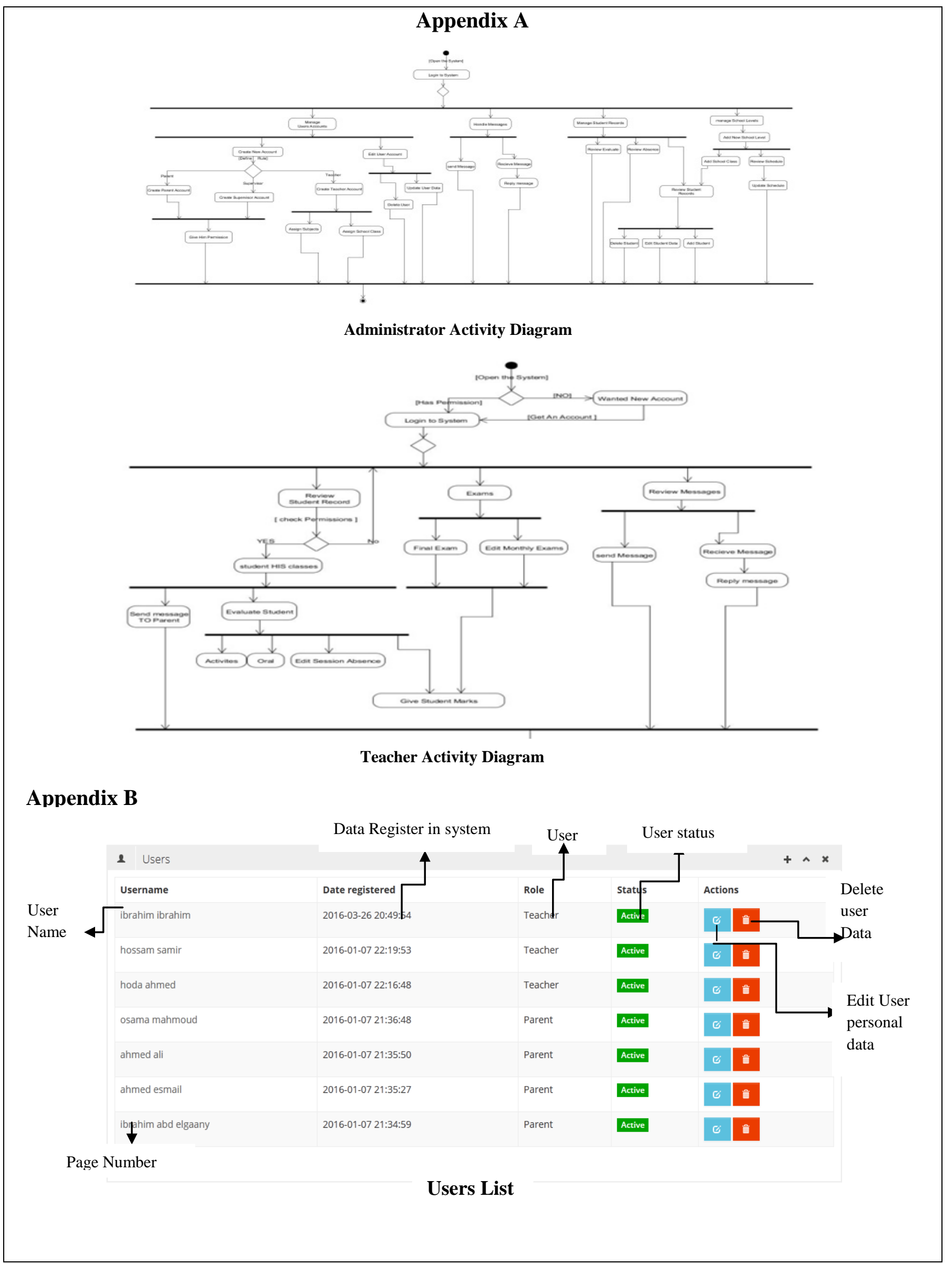




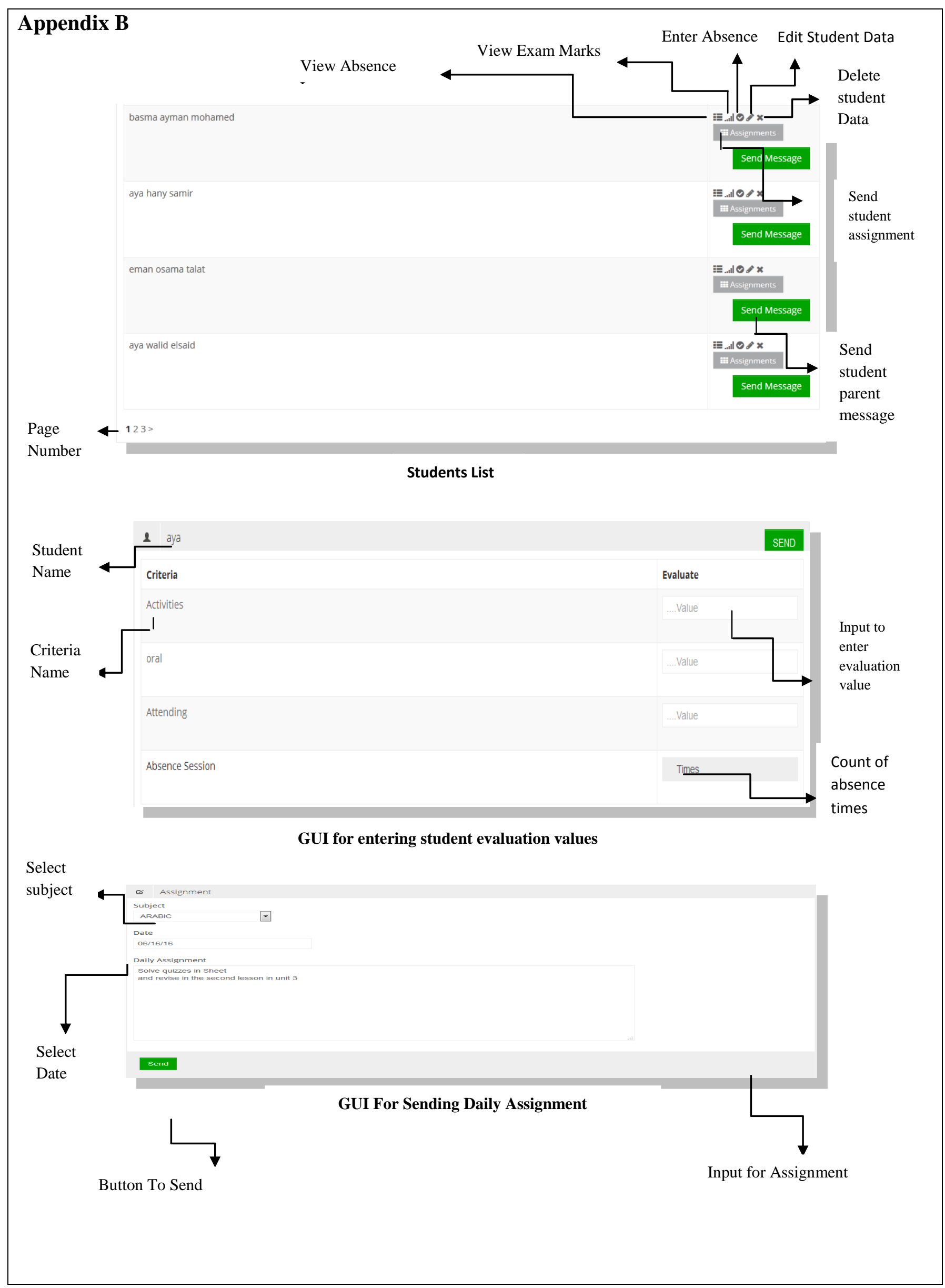




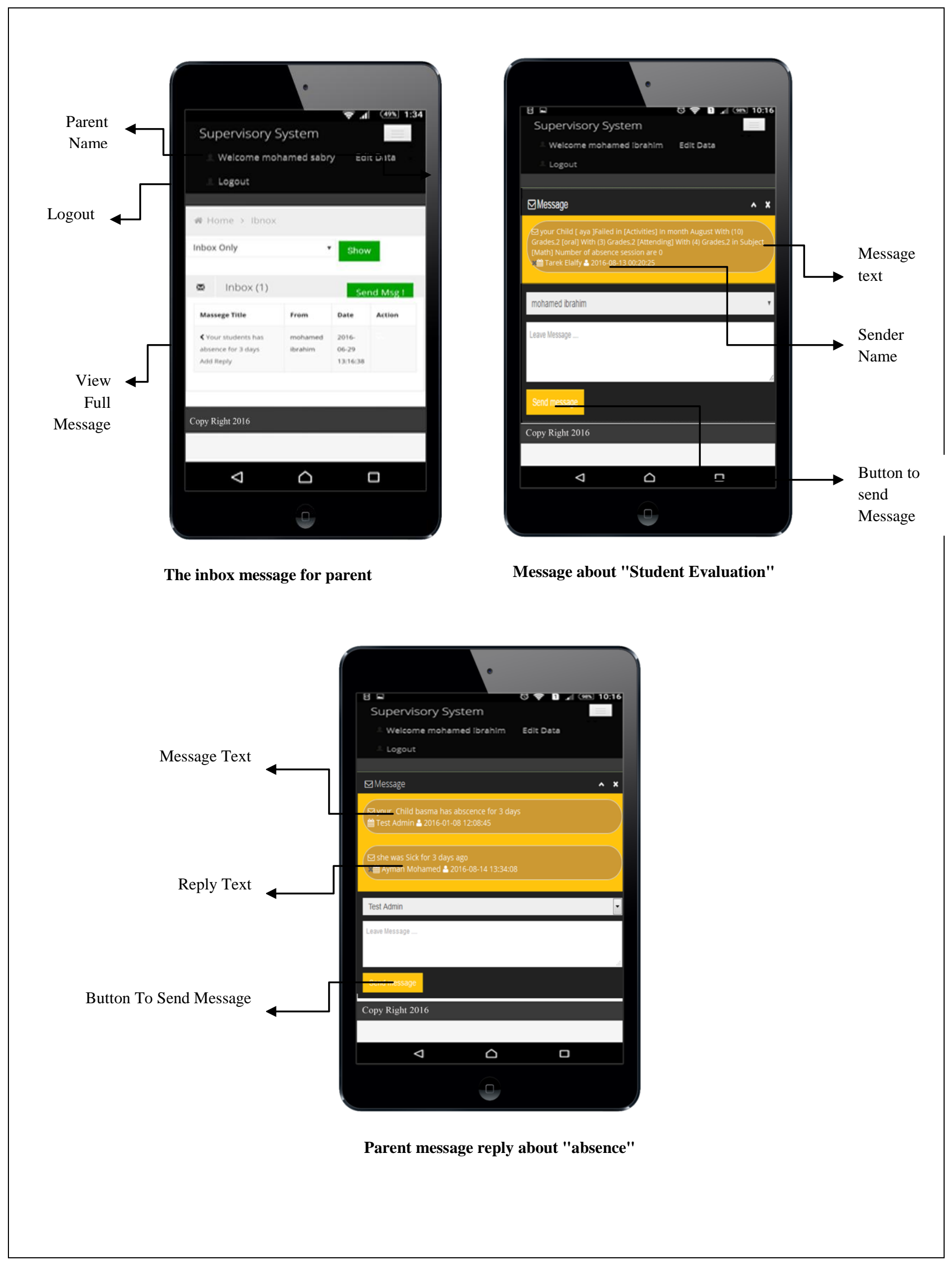

